\title{
Isolated gastroduodenal Crohn's disease in a ten-year-old girl
}

\author{
Peter Malleson \\ M.R.C.P. \\ Department of Haematology, Hospital for Sick Children, Great Ormond Street, London
}

\begin{abstract}
Summary
The first case of a child with gastroduodenal Crohn's disease and no other intestinal lesions is described. She presented with persistent anaemia and failure to thrive. There was megaloblastosis due to $B_{12}$ deficiency secondary to absent intrinsic factor. The diagnosis was delayed for nearly 3 years and then treatment with steroids and azathioprine resulted in rapid clinical improvement. The diagnostic possibility of Crohn's disease in unusual sites should be considered in any child with unexplained failure to thrive.
\end{abstract}

\section{Introduction}

Crohn's disease in childhood is often difficult to diagnose, so that a low threshold of suspicion is required (O'Donaghue and Dawson, 1977). This report describes a child with severe failure to thrive due to isolated gastroduodenal Crohn's disease, whose diagnosis and treatment were delayed because of the extremely unusual site of the disease.

\section{Case report}

The patient first presented in January 1975, aged 10 years, with symptomatic anaemia and weight loss of one month's duration. The $\mathrm{Hb}$ level was $5.7 \mathrm{~g} / \mathrm{dl}$ with evidence of iron deficiency, serum iron $7.9 \mu \mathrm{mol} / \mathrm{l}$ (normal $14.3-21.5 \mu \mathrm{mol} / \mathrm{l}$ ), total iron binding capacity $84 \cdot 1 \mu \mathrm{mol} / \mathrm{l}$ (normal 43.0-64.4 $\mu \mathrm{mol} / \mathrm{l})$. A bone marrow aspiration showed megaloblastic changes and no iron stores. Folate levels were normal and plasma $B_{12}$ slightly low, $145 \mathrm{ng} / 1$ (normal 150-1000 $\mathrm{ng} / \mathrm{l}$ ). There was no evidence of blood loss and as her diet was vegetarian and the calorie intake extremely low, a diagnosis of nutritional iron deficiency was made. She did not improve on iron supplements and reinvestigation in January 1976 showed a definite $B_{12}$ deficiency $(110 \mathrm{ng} / \mathrm{l})$.

A barium meal showed abnormalities of the stomach with mucosal irregularity suggestive of widespread ulceration on the greater curvature. There was little peristalsis and the pylorus was fixed and open. The duodenum was dilated and peristalsis was disturbed as shown by a to-and-fro movement of the barium. Gastroscopy showed an atrophic, red, finely granular mucosa with marked vascularity of the stomach and coarse granulation of the duodenum. Biopsy histology showed changes of active chronic gastritis with intestinal metaplasia, and no granulomata were seen. A pentagastrin test showed anacidity with almost absent intrinsic factor. A Schilling test was consistent with $\mathrm{B}_{12}$ malabsorption due to intrinsic factor deficiency, urinary excretion of ${ }^{57} \mathrm{Co}$-labelled $\mathrm{B}_{12}$ being $1.4 \%$ before and $12.4 \%$ after intrinsic factor (normal $>10 \%$ ). Parietal cell and intrinsic factor antibodies were not found and no acid fast bacilli could be isolated on gastric washings.

The possibility of Crohn's disease was raised but thought unlikely; however, she failed to thrive despite monthly $\mathbf{B}_{\mathbf{1 2}}$ injections and her nutritionat intake remained very poor because of anorexiag In October 1977 gastroscopy combined wit colonoscopy was performed. There was again $\overline{\vec{z}}$ diffusely friable and reddened stomach mucosa with an unusual villous pattern in the duodenal cap. Biopsies of the stomach showed a mixed acute and chronic inflammatory infiltrate with a few well defined non-caseating granulomata (Fig. 1). The duodenum showed similar changes but no granulomata. The colon and terminal ileum were normal endoscopically and histologically.

A diagnosis of isolated gastroduodenal Crohn's disease was made and after an initial period of nasogastric tube feeding she was treated with prednisolone $(2 \mathrm{mg} / \mathrm{kg} /$ day $)$. Azathioprine at $1 \mathrm{mg} /$ $\mathrm{kg} /$ day, increasing to $2 \mathrm{mg} / \mathrm{kg} /$ day, was added as the steroids were reduced to an alternate day regimen. A dramatic improvement in well-being, appetite and weight occurred, nearly $10 \mathrm{~kg}$ being gained in 4 months (Fig. 2). Four months later a repeat endoscopy showed a virtually normal stomach mucosa and, although there were 2 small aphthoid ulcers in the duodenum, this, too, was greatly improved.

\section{Discussion}

This girl is the first reported case of isolated gastroduodenal Crohn's disease in a child; the occurrence of achlorhydria and intrinsic factor deficiency in gastroduodenal Crohn's disease also appears to be unique in this child. 


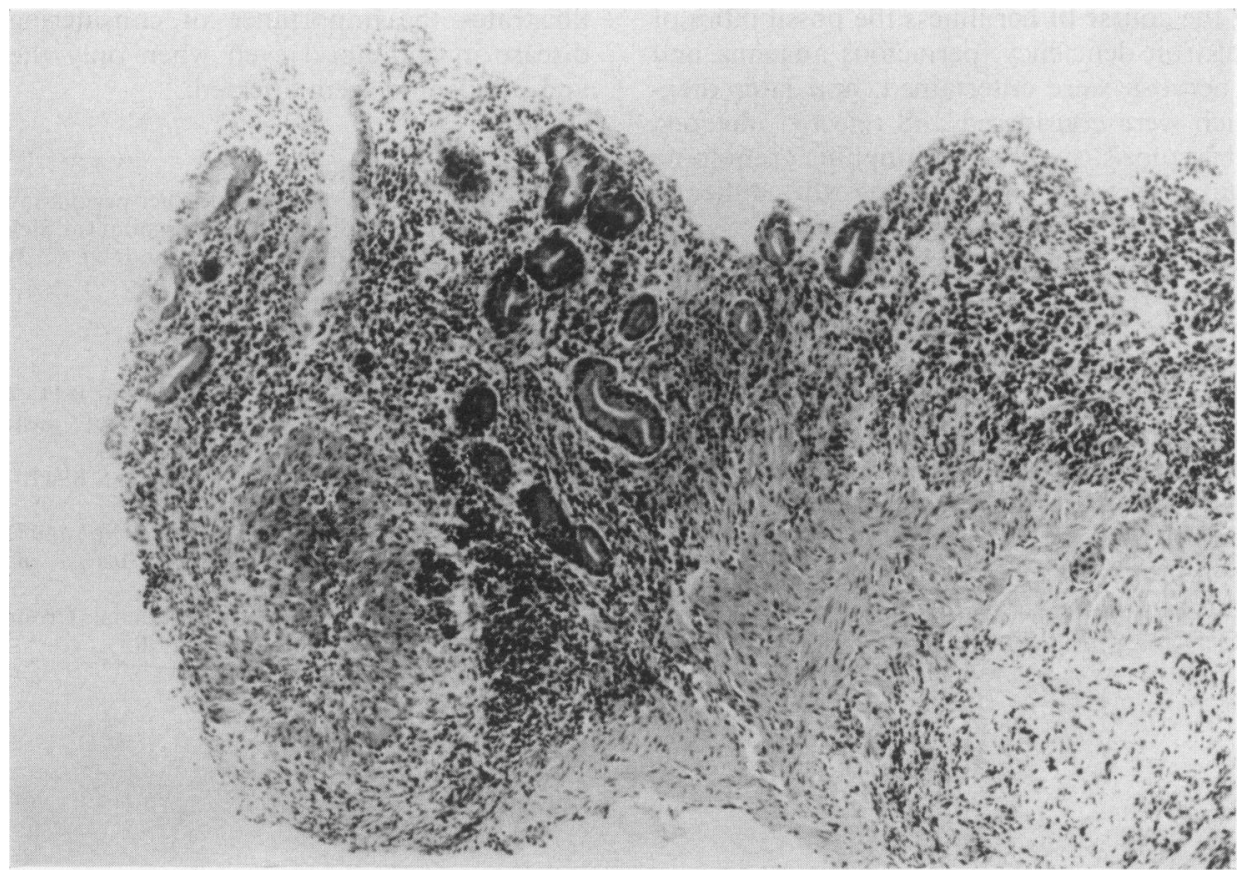

FIG. 1. Low power photomicrograph of gastric biopsy showing non-caseating granulomata in mucosa $(\mathrm{HE}, \times 100)$.

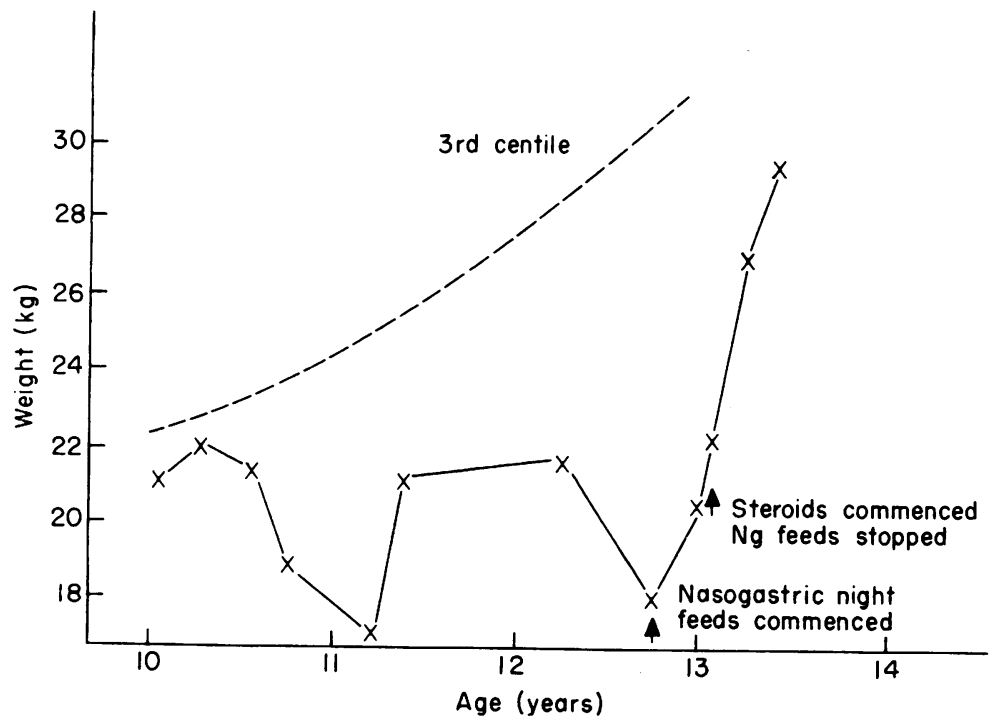

FIG. 2. Weight chart showing response to nasogastric feeds and steroids. - - - Tanner and Whitehouse Standard (1966). 
During the course of her illness the possibilities of nutritional iron deficiency, pernicious anaemia and anorexia nervosa were entertained, and later diagnoses which were considered and rejected included gastric tuberculosis, syphilis, eosinophilic granuloma and fungal infections, emphasizing the difficulty in making the diagnosis of Crohn's disease.

The endoscopic and X-ray features are similar to those previously described (Danzi et al., 1976). The difficulty of obtaining a histological diagnosis by endoscopic biopsy in Crohn's disease of the stomach and duodenum (Pryse-Davies, 1964; Nugent, Richmond and Park, 1977) is well illustrated by the present case. However, granulomata were eventually obtained on the third biopsy.

Thirteen per cent. of patients with Crohn's disease develop symptoms before the age of 16 years and, as with this child, the delay in diagnosis is usually 3 years (O'Donaghue and Dawson, 1977). This case illustrates the importance of considering Crohn's disease in childhood even when only the stomach and duodenum seem affected.

\section{Acknowledgements}

My thanks to Dr J. Chessells for her permission to present this case and to Dr John Harries (Hospital for Sick Children), Dr A. Blackshaw, Dr A. Dawson and Dr C. Williams (St Bartholomew's Hospital) for their help.

\section{References}

Danzi, J.T., Farmer, R.G., Sullivan, B.H. \& Rankin, G.B. (1976) Endoscopic features of gastroduodenal Crohn's disease. Gastroenterology, 70, 9.

NugENT, F.W., Richmond, M. \& PARK, S.K. (1977) Crohn's कै disease of the duodenum. Gut, 18, 115.

O'Donaghue, D.P. \& Dawson, A.M. (1977) Crohn's disease in childhood. Archives of Disease in Childhood, $52,627$.

Pryse-Davies, J. (1964) Gastroduodenal Crohn's disease. Journal of Clinical Pathology, 17, 90. 